\title{
Sobre corpos e excessos: performance e política em Gorduras Saturadas de Miro Spinelli
}

\section{About bodies and excesses: performance and politics on Gorduras Saturadas of Miro Spinelli}

Manolo Kottwitz ${ }^{1}$

Ana Lúcia Mandelli de Marsillac ${ }^{2}$ 


\section{Resumo}

A arte da performance pode ser considerada, sui generis, um potente motor de problematizações sobre certos paradigmas éticos, estéticos e políticos que envolvem o corpo na atualidade. Este artigo procura analisar de maneira crítica as relações produzidas entre a apresentação da performance Gordura Trans \#3 / Gordura Localizada \#1 de Miro Spinelli, sua recepção e reverberações nas redes sociais. Sob a luz das filosofias de Baruch de Spinoza, Gilles Deleuze e Jacques Rancière, exercitamos uma leitura das ressonâncias da performance, as quais Spinelli intitula Gorduras Saturadas. Nossa intenção é articular a leitura da obra à maneira como os diferentes discursos da recepção do público evidenciam determinados tipos de experiência e os processos de subjetivação decorrentes do acontecimento.

Palavras-chave: Performance; Ética; Política; Corpo; Processos de Subjetivação.

\section{Abstract}

Performance art may be considered, sui generis, a powerful motor of problematizations over certain ethical, esthetical and political paradigms that mantles the body nowadays. This article seeks to analyze in a critical manner the relations produced between the presentation of Miro Spinelli's Gordura Trans \#3 / Gordura Localizada \#1, it's reception and reverberation on social media. Under the lights of the philosophies of Baruch Spinoza, Gilles Deleuze and Jacques Rancière, we exercise a reading of the performance's resonances, named Gorduras Saturadas by Spinelli. Our intention is to articulate this work's reading to the way how the different discourses of the reception of the public show certain types of experience and the

subjectivation processes derived from the event.

Keywords: Performance; politic; aesthetic; body; subjectivation processes 


\section{Introdução}

Fruto de uma pesquisa de mestrado sobre as interfaces entre performance, política e subjetividade, este artigo é um recorte que procura analisar as potências da arte da performance como um dispositivo produtor de encontros e variações sobre as experiências. Para pensar a relação socialmente produzida entre o que se entende por corpo, performance e política, neste texto, investimos em uma leitura das reverberações da performance Gordura Trans \#3 / Gordura Localizada \#1 de Miro Spinelli (2015) ${ }^{3}$ , que proliferaram na internet ${ }^{4}$ e nas mídias sociais no ano de 2015 e que Miro chamou de Gorduras Saturadas. Analisamos esta performance como acontecimento estético, envolvendo práticas que contestam os habituais regimes de apresentação do sensível, os quais tendem a ser definidos a priori como representação ideal de uma realidade já constituída. Encontramos, no trabalho de Miro, a potência de agir na produção de movimentos de resistência e criação frente à ideologia dominante que se impõe como verdade. Sua potência, entendida no contexto de uma cena polêmica sobre o real, articula as mais diversas maneiras de povoar seus tempos e espaços, produzindo composições singulares e inusitadas a partir daquilo que torna sensível, ultrapassando os dados da experiência do já dito e já pensado, ou seja, do instituído. No encontro engendrado no contexto da performance, os corpos e sujeitos envolvidos na experiência tornam-se outros, criando novas conexões, compondo novas paisagens constituintes de um território inédito, tendo em vista que o trabalho de Mirio, antes de reproduzir, copiar ou simplesmente representar um mundo estável e finito em si, opera dispositivos que mobilizam forças ativas contra o stablishment, produzindo assim uma experiência mais viva dos corpos relacionados em um contexto de arte.

Procuramos exercitar a análise das reverberações da performance de Miro Spinelli, pois entendemos que sua prática artística trabalha de maneira crítica sobre a matéria sensivel de uma comunidade. A partir deste viés, colocamos uma série de questões para conduzir nossas reflexões sobre a arte da performance, suas relações e imbricamentos com as políticas do corpo, bem como a política da arte e a dinâmica dos afetos na produção de subjetividade. Buscaremos analisar de que modo a performance de Spinelli opera a produção de cenas polêmicas sobre a realidade e como esta ficção reorganiza os dados da experiência sensível na composição (produção de forças ativas) ou na decomposição (produção de forças reativas) das formas de vida dentro de um determinado recorte de tempo e espaço artísticos experimentado em comunidade.

Apesar de a performance trazer em seu título um jogo semântico que problematiza ao mesmo tempo o corpo gordo e o corpo transgênero, optamos por desdobrar nossa perspectiva a partir de outro recorte, o qual diz respeito a uma ética dos corpos que está aquém e além das discussões de gênero e outros estatutos normativos da sociedade. Propomos o exercício de pensar a produção de um contexto político, no qual a performance funda uma comunidade litigiosa em torno de determinados assuntos que tem o corpo como objeto.

\footnotetext{
${ }^{3}$ Gordura Transé otítulo de um dos processos investigativos de Miro Spinelli. Explorando as tensões discursivas sobre o corpo gordo, a cada performance Spinelliexperimenta a manipulação de diferentes matérias e materiais gordurosos sobre seu próprio corpo. A série de Gordura Trans está atualmente em sua $14^{\mathrm{a}}$ experimentação. ${ }^{4}$ Miro mantém o site http://gordura-trans.tumblr.com/, um repositório sobre o processo de Gordura Trans, reunindo imagens das performances Gordura Trans \#1, \#2 e\#3, além de textos e a reunião de algumas Gorduras Saturadas que conseguiu recolher na web. Recentemente, Miro Spinelli fez uma exposição das Gorduras Saturadas, agrupando dezenas de recortes e montagens de textos com comentários de internautas e materiais gordurosos.
} 


\section{O acontecimento: da performance às reverberações}

Nossa análise parte inicialmente das ressonâncias provocadas pela ação de Miro Spinelli nas redes sociais. Por não termos presenciado a performance que produziu estas tensões, nossa narrativa baseia-se em seus registros e nas suas reverberações ${ }^{5}$, as Gorduras Saturadas, e , como quem escreve sobre algo, a narrativa a seguir também é um delírio sobre a performance, afim de situá-la minimamente em nosso recorte.

No ano de 2015, aconteceu na Universidade Federal da Bahia a segunda edição do Seminário Internacional Desfazendo Gênero ${ }^{6}$, a performance Gordura Trans \#3/ Gordura Localizada \#1 estava presente na programação junto a outras centenas de atividades. Em meio a um pátio aberto, entre tantos outros corpos, um corpo em especial atualizava as tensões do espaço que adentrava. Poderia ser um corpo qualquer, destes padronizados, sintonizados com os ideais das indústrias da beleza e da saúde, reproduzidos nas revistas especializadas no assunto. Talvez, dessa forma, não precisasse se apresentar, talvez até passasse despercebido, quem sabe até não acontecesse absolutamente nada demais, em decorrência das forças do hábito que acomodam os sentidos. Poderia ser um corpo qualquer, mas era um corpo irredutível, um corpo que não pedia passagem: ele abria caminho. Este corpo então ocupa um lugar que o faz figura destacada da paisagem. Corpo trans, corpo gordo, nu, indecifrável. O ritual de uma reivindicação de potência do corpo, da revolta do corpo contra as forças que enclausuram e embotam os poros com uma moral saturada, se inicia. Miro Spinelli rasga seu tecido adiposo numa dança engordurada pelo óleo de dendê. Escancara as dobras, os pelos e "uma infinidade de monstrinhos que ninguém quer ver" (Spinelli, 2015) e faz do movimento uma dança de guerra biopolítica ${ }^{7}$. Ao termo do ritual, o corpo é lavado. Corpo trans, corpo nu, corpo gordo, corpo pleno de potência.

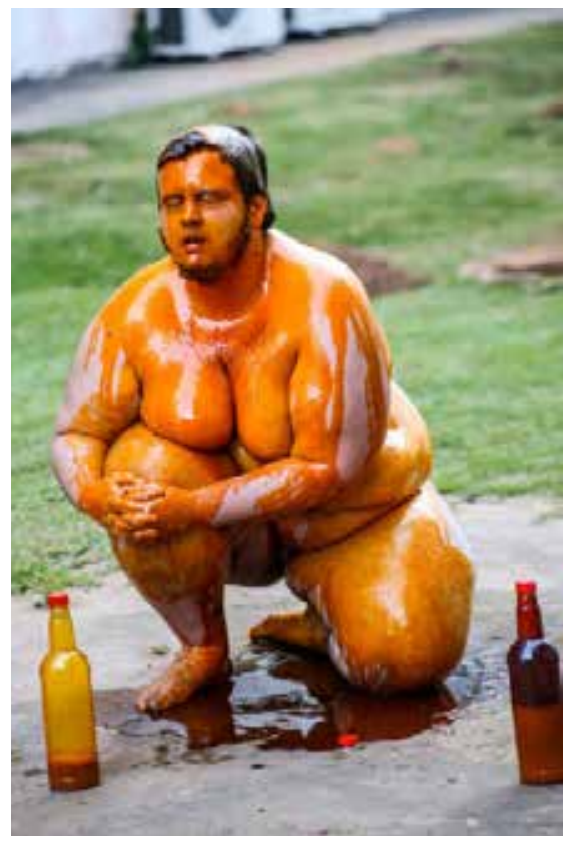

\footnotetext{
${ }^{5}$ Certamente, há que se considerar que há diferenças na leitura de uma performance quando se experiência ela presencialmente e quando se analisa apenas seus registros, mas isso não implica em juízos de valor e sim em perspectivas singulares.

${ }^{6} \mathrm{O} 2^{\circ}$ Seminário Internacional Desfazendo Gênero aconteceu de 04 a 07 de setembro de 2015, no Teatro Castro Alves e na Universidade Federal da Bahia/PAF III, na cidade de Salvador, Bahia. Todos os materiais referentes ao evento e sua programação podem ser conferidos no portal: http://www.desfazendogenero.ufba.br/.

${ }^{7} \mathrm{~A}$ biopolítica é um conceito foucaultiano que implica uma análise histórica do quadro de racionalidade política a partir do liberalismo. Para Foucault (1997), a biopolítica opera movimentos agônicos nas políticas dos corpos a partir do âmbito da gestão da saúde, da higiene, da sexualidade, fomentando as bases de uma comunidade pautada em padrões de saúde, beleza e normalidade.
} 
As reverberações de Gordura Trans \#3 / Gordura Localizada \#1 se disseminaram de modos diversos, nos quais podemos identificar dois grandes fluxos de forças: os ativos, os reativos e seus derivados. O encontro dos corpos no contexto dessa performance produziu movimentos nos processos subjetivos que ora afirmam devires ativos, oferecendo graus de liberdade a serem experimentados pelos corpos ${ }^{8}$, ora convocam os devires reativos para que recalquem essa estranha moção de liberdade.

Podemos apreender as marcas sensíveis desses devires reativos através daquilo que Miro Spinelli chamou de Gorduras Saturadas: as intervenções anônimas feitas a partir dos registros fotográficos da performance que começaram a circular nas mídias sociais imediatamente após a apresentação na UFBA. Além das montagens declaradamente pejorativas, também foi recorrente a proliferação de discursos preconceituosos e zombeteiros ${ }^{9}$ sobre questões com o corpo gordo, corpo trans e também sobre as formas do fazer artístico contemporâneo. Todos esses comentários, sem exceção, produziram tensões antagônicas em relação às pautas problematizadas pela performance, em nome de uma ortodoxia do corpo, ou seja, um conjunto abstrato de crenças e valores produzidos historicamente pela sociedade e estabelecidos como norma.
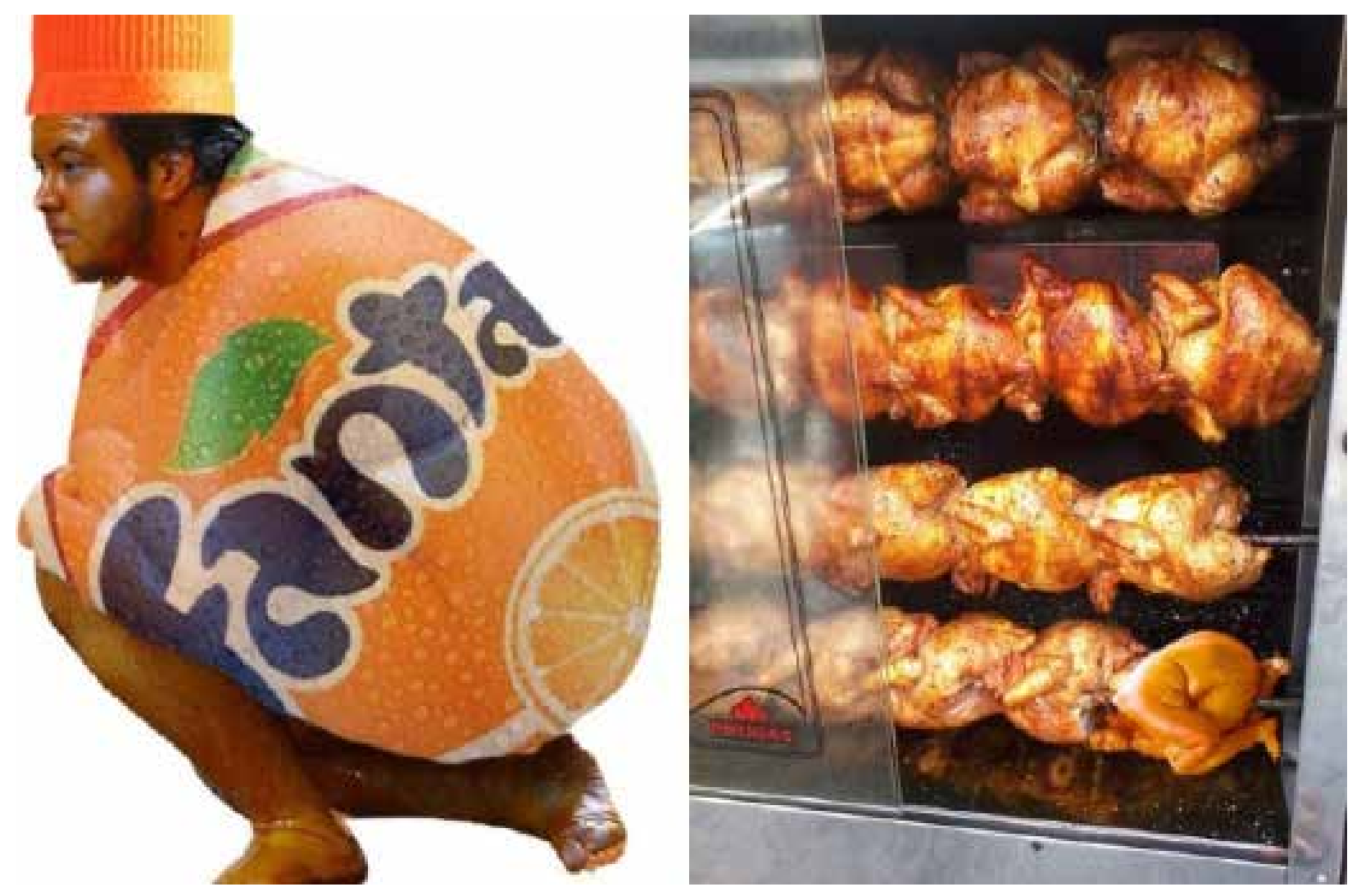

Imagem 2 - Gorduras Saturadas (intervenção anônima sobre os registros de Gordura Trans \#3 / Gordura Localizada \#1) Fonte: bobagento.com

\footnotetext{
${ }^{8}$ Destacamos a construção de um espaço de discussão artística e acadêmica, com a publicação de artigos, exposição fotográfica de registros, etc.

${ }^{9}$ Um dos sites que canalizou as reverberações foi o bobagento.com, um canal que reúne materiais de humor de todos os tipos. Link: http://bobagento.com/aluno-apresenta-seu-tcc-de-humanas-em-universidade-da-bahia/
} 


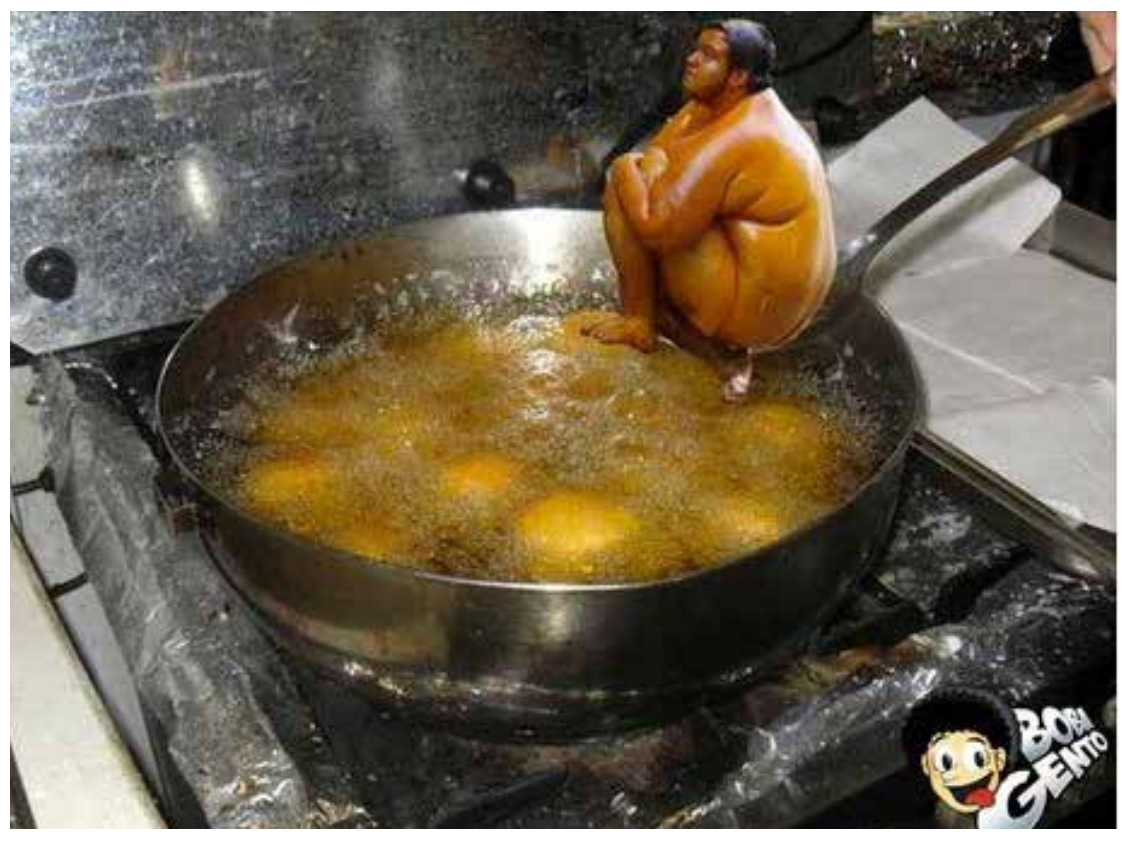

Imagem 3 - Gorduras Saturadas (intervenção anônima sobre os registros de Gordura Trans \#3 / Gordura Localizada \#1) Fonte: bobagento.com

\section{Ética, estética e política em Gorduras Saturadas}

A apresentação do corpo de Miro Spinelli banhando-se numa película viscosa de óleo de dendê, dançante em seu xamanismo biopolítico, nos joga em um campo de batalha. Podemos aproximar a construção dessa cena àquilo que Deleuze e Guattari (2012) chamaram de "Corpo sem Órgãos" (CsO): o campo de batalha sobre o qual "dormimos, velamos, que lutamos e somos vencidos [...] que descobrimos nossas felicidades inauditas e nossas quedas fabulosas, que penetramos e somos penetrados, que amamos" (Deleuze; Guattari, 2012, p. 12). Gordura Trans \#3/Gordura Localizada \#1 pode ser visto como um tipo específico de batalha, empreendida com, sobre e em um corpo que se descola do consenso, da doxa e do senso comum. É um movimento ao qual é preciso sempre estar atento, pois, ao sublinhar a dimensão política do corpo, de um corpo que desafia o instituído, é claro que "não deixarão você experimentar em seu canto" (Deleuze; Guattari, 2012, p. 12), é preciso resistir, não a marteladas, não destrutivamente, "mas com uma lima muito fina" (Deleuze; Guattari, 2012, p. 25).

A experiência de ser atravessado pela performance de Spinelli e as reverberações que dela ecoam, nos coloca em um território onde as convenções não cessam de ser contestadas e desabar, nos oferecendo a experiência de um paradoxo, quer dizer, da produção de um discurso que não combativo, opositivo, mas paralelo, que produz desvios na doxa. Se a performance de Miro é paradoxal, ela o é na medida em que oferece novas conjecturas e novos modos de pensabilidade sobre o real dos corpos, o intangivel que escapa ao discurso dominante. Portanto, pode-se olhar para o acontecimento desta ação como uma para-doxa, um movimento que produz linhas de fuga e propõe lógicas que fogem à ortodoxia, à consensualidade, e é nesse ponto que a sua força transformadora, sua potência política, é evidenciada. 
$\mathrm{Na}$ perspectiva micropolítica, ao oferecer a possibilidade de experiências estéticas, a performance abre novos possíveis, dispara novos devires do corpo e ativa novos pontos de vista sobre a liberdade: o corpo age, experimenta um tempo e um espaço vivo, desapossado de sua esterilidade condicionada pela lógica consensual. De acordo com Eleonora Fabião, é justamente esta a potência da performance:

[...] desabituar, des-mecanizar, escovar a contrapelo. Trata-se de buscar maneiras alternativas de lidar com o estabelecido, de experimentar estados psicofísicos alterados, de criar situações que disseminam dissonâncias diversas: dissonâncias de ordem econômica, emocional, biológica, ideológica, psicológica, espiritual, identitária, sexual, política, estética, social, racial... (Fabião, 2008, p. 237).

Cada performance é uma, dentre incontáveis respostas, sempre provisórias, para a pergunta espinosista "o que pode o corpo?". Cada performance é uma reivindicação de potência, uma retaliação das forças que aprisionam as potências do corpo, em nome de uma ética e de uma política que se mostram opostas àquelas que buscam adestrar o corpo. Na performance, muitas vezes, os corpos experimentam o limite da sua potência de agir, exercitando o que a psicanalista Suely Rolnik chama de "o corpo-que-sabe". Este termo foi criado para se referir ao corpo ético e expressa a capacidade desse corpo em produzir as condições de possibilidades para medir suas distâncias e velocidades numa trama de afetos. $O$ "corpo-que-sabe" é um "corpo que sabe dos efeitos do outro na própria textura, na própria consistência de si" (Rolnik, 2013), um corpo que busca se aproximar da noção de liberdade, tal como desenvolvida por Spinoza (2014a, 2014b).

A liberdade, para Spinoza (2014a, 2014b), torna-se possível à medida que o sujeito humano se aproxima do terceiro gênero do conhecimento que é um pensar/ agir, pensar/criar, ultrapassando as marcas da consciência e os limites da razão. $O$ corpo, na fase do terceiro gênero, é dotado de um poder de invenção e rigor sobre si. Além de conhecer e entender o que está no "fora", ele inventa e cria novos modos de vida, maneiras outras de pertencimento, considerando que o constrangimento do corpo pelas forças externas é uma condição necessária e que este só se constitui em sua relação com tais forças. Nesse estágio produtivo, o sujeito ultrapassa aquilo que é, produz uma nova maneira de existir e se liga diretamente com a noção de liberdade. Ao operar um conhecimento sensível, que se dá através do corpo, a performance produz um campo de experiência estética que oferece aos sujeitos envolvidos (artista e público) a possibilidade de experimentar graus de liberdade.

Trata-se, assim, de refletir sobre um corpo que amplia suas condições de medir as distâncias e as velocidades, as intensidades dos afetos para os quais seu corpo está aberto e para a sua consequente potência de agir na reinvenção de si. Entretanto, entende-se este conhecimento do corpo como virtualidade, que só se efetua ao se tornar sensível, isto é, ao se atualizar num campo de forças comum atribuído de sentido, "quando ele se 'performatiza' num agir, que pode ser uma mudança de modo de existência, que pode ser uma obra de arte" (Rolnik, 2013).

A ideia do "Corpo sem Órgãos" como um corpo ético é vislumbrada na própria interrogação retórica de Deleuze e Guattari (2012, p.17), ao colocar a Ética de Spinoza como o "grande livro" do CsO. Esta conexão interessa a partir do momento em que 
nos aproximamos do empreendimento iniciado por Spinoza. A liberdade do corpo é a liberdade do $\mathrm{CsO}$, liberdade de estar aberto às intensidades, mas também uma liberdade como efetuação de potência, como causa de si. É igualmente a liberdade do corpo-que-sabe a direção dos seus bons encontros, que amplia seu conhecimento sobre a política das paixões e a dinâmica dos afetos para produzir mais potência.

A arte da performance convoca os corpos para agir, produz uma força movente. Trata-se menos de ensaiar um movimento-resposta do que uma tomada de posição imediata no aqui-e-agora. Agir é tornar sensível, tornar visíveis as forças antes invisíveis. Entretanto, não podemos afirmar que uma performance sempre age no sentido de efetuar uma transformação efetiva, em termos micropolíticos, e produzir novas linhas de força nos corpos, entendidas como processos de subjetivação ativos. Há certos casos em que a performance pode produzir visibilidade sobre linhas duras nos processos de subjetivação dos sujeitos da experiência, tornando visíveis marcas de uma subjetividade embotada por uma micropolítica colonizada e enraizada nos equívocos do convencionalismo e do hábito.

Não se sabe exatamente o que, mas algo necessariamente se produz e, ao mesmo tempo em que o performer gera essa visibilidade, ele faz perfurações, abre caminhos, fissuras nas subjetividades e faz passar algo. Possibilita que algo 'estranho' entre, que novos fluxos e novas intensidades sejam trocados entre o mundo-corpo e corpo-mundo, desorganizando, desmontando a rigidez condicionada pelo hábito e pelo consenso. Ações performáticas podem ter ou não fins engajados em determinada questão, entretanto seus modos de existir e acontecer sempre produzem tensões no campo do político, porque suspendem ou colocam em xeque valores e hábitos estabelecidos. Neste sentido, Gordura Trans canta a liberdade dos corpos e enfrenta o regime moral ao apresentar uma ação que reitera o inaceitável pelo senso comum, em nome de uma política de livre gestão dos corpos.

Os paradigmas sociais e a doxa costumam compartilhar o estatuto da Lei, esse grande conjunto de normas sociais baseadas na experiência humana, para dizer o bem e o mal dos corpos, para qualificar moralmente os atos e julgá-los corretos ou incorretos dentro de um determinado quadro sociocultural. É do domínio da performance e do performer desestabilizar o instituído pela lei e produzir, através de suas ações, movimentos de desidentificação e dissenso: desterritorializar o instituído. Esta zona de enfrentamentos é o próprio plano de imanência onde o desejo toma consistência. Ali onde há moral, há também um padre que diz "falta", e no espaço onde o corpo do performer faz morada, há uma ética que diz "deseje mais, é preciso por um fim no juízo de Deus", pois "que existe uma alegria imanente ao desejo, como se ele se preenchesse de si mesmo e de suas contemplações, fato que não implica falta alguma" (Deleuze; Guattari, 2012, p. 19).

O agir da performance lança os corpos em processos de experimentação que fazem pensar o que antes era impensável, invoca forças criadoras que vetorizam as subjetividades para fora: dessubjetivação, linhas de fuga. Mas o que necessariamente foge? Certamente não se trata de uma corrida temerosa em busca de um "deus-que-nos-acuda". É antes um fazer fugir, fazer escoar a subjetividade, reduzi-la sem aniquilá-la (sob o risco de aniquilar-se a si próprio). Ao mesmo tempo em que a experimentação desembota algo e faz fugir, algo também é sugado para dentro. En- 
tretanto, não se trata de um movimento seletivo, não se escolhe o que sai e o que entra, mas pode-se regular as intensidades: esta é a habilidade do corpo-que-sabe; prudência na experimentação de distâncias e velocidades.

A performance de Miro Spinelli oferece escopo, neste duplo movimento, para pensarmos as possibilidades de aproximações e divergências entre a arte política, um fazer artístico engajado num determinado tipo de luta social, e uma política da arte. Nesse aspecto é necessário levarmos em conta que a arte não se torna política ou engajada simplesmente por apresentar uma contestação de valores estabelecidos ou constatar a existência deles, não é mais nem menos política por apresentar um recorte de certas estruturas sociais. "Ela é política antes de mais nada pela maneira como configura um sensorium espaço-temporal que determina maneiras do estar junto ou separado, fora ou dentro, face a ou no meio de..." (Rancière, 2010, p. 46).

Poderíamos afirmar que Gordura Trans \#3/Gordura Localizada \#1 e as Gorduras Saturadas se apresentam na intensidade de uma arte política, ainda que não se tratem de ações representativas de uma luta social, mas sim da afirmação de formas de vida que questionam os modelos e ideais dominantes na atualidade. Não é a reivindicação de um direito de existir, mas a própria existência em ato. Podemos dizer que ela produz uma cena política e instaura uma comunidade litigiosa ao recortar um espaço e um tempo singular e povoá-lo com intensidades que determinam uma forma específica de experiência (Rancière, 2009).

Ao mapearmos e olharmos para as Gorduras Saturadas, as reverberações de Gordura Trans..., conseguimos pontuar que, de um modo bastante incisivo, a ação de Spinelli produziu uma experiência de dissenso. Esta experiência decorre, sobretudo, da apresentação de um corpo que, aos modos do costume, não é permitido ocupar o lugar o qual ocupa, ao se colocar nu, executando uma ação que foge aos princípios do cotidiano. Neste sentido, entendemos que, ao modificar as relações sensíveis entre espaço, tempo e regimes de signos e significações, a performance de Spinelli sublinha a política entre os corpos.

\footnotetext{
Porque a política, bem antes de ser o exercício de um poder ou uma luta pelo poder, é o recorte de um espaço específico de "ocupações comuns"; é o conflito para determinar os objetos que fazem ou não parte dessas ocupações, os sujeitos que participam ou não delas, etc. Se a arte é política, ela o é enquanto os espaços e os tempos que ela recorta e as formas de ocupação desses tempos e espaços que ela determina interferem com o recorte dos espaços e dos tempos, dos sujeitos e dos objetos, do privado e do público, das competências e das incompetências, que define uma comunidade política (Rancière, 2010, p. 46).
}

A potência de Gordura Trans constitui-se a partir da ação inesperada de um corpo gorduroso, transgênero, banhando-se num líquido igualmente gorduroso, apresentando uma cena que contraria o aceitável. Atualmente, a corrida pelo moralmente bom e belo invocado sobre o corpo, alavancada pela lógica neoliberal, através da mídia, das indústrias de cosméticos, farmacêutica, entre outras, implica em inúmeras práticas e formas de viver que condicionam o corpo a se encaixar numa determinada lógica sociocultural, numa determinada doxa do corpo. Cultua-se um corpo magro, heteronormativo, que deveria expulsar as impurezas da gordura, mantendo a boa 
forma e as certezas no que tange à sexualidade. Por outra via, em uma perspectiva crítica, Miro Spinelli reitera o direito de um corpo entendido como desviante pelo consenso, cria condições espaço-temporais que disseminam dissonâncias de diversas ordens: social, estética, ideológica e sexual, na apresentação formal dos corpos.

Ao colocar o corpo a ocupar um espaço entendido pelo consenso como inapropriado para o contexto, opera-se uma disjunção entre o aceitável e o apresentado. Coloca-se em questão o ideal moral de um corpo que deveria transcender suas imperfeições através de um condicionamento rígido. Ao mesmo tempo, coloca em jogo o posicionamento ético de um corpo que afirma seu direito à existência, como disse Spinelli (2015): com toda a "infinidade de monstrinhos que ninguém quer ver".

Essa disjunção apresenta outras duas modalidades de pensamento que Jacques Rancière (2009; 2010) nos propõe: a política da estética e a estética da política. Em primeiro lugar, antes de determinar formas sensíveis de apresentação de um objeto ou acontecimento estético em um lugar de arte, a política da estética conduz a uma metapolítica, isto é, ao "projeto de realizar realmente aquilo que a política realiza apenas aparentemente: transformar as formas da vida concreta, enquanto a política se limita a mudar as leis e as formas estatais" (Rancière, 2010, p. 50). Propõe-se, então, que a política da estética se trata de uma metapolítica, visto que ela, quando elaborada e compreendida em um contexto de arte, encontra-se noutro lugar que não o da política de gestão governamental do Estado. A política da estética, ao fazer agir as formas de vida rumo a uma transformação concreta, implica numa ética dos corpos e das formas sensíveis, antes de uma moral que, através de leis e regimentos, direciona os mesmos vetores, mas de modo apenas parcial e, sobretudo, esvaziado de sua potência transformadora.

De outro modo, o regime estético coloca em jogo uma relação de independência e indiferença da obra no que diz respeito à sua produção e sua destinação: a performance produz ou não política independente do artista querer produzi-la. A eficácia estética diz respeito à suspensão de qualquer relação determinável entre a intenção do artista e da recepção de um público, remetendo diretamente à noção de "coeficiente artístico" elaborado por Marcel Duchamp:

No ato criador, o artista passa da intenção à realização, através de uma cadeia de reações totalmente subjetivas. Sua luta pela realização é uma série de esforços, sofrimentos, satisfações, recusas, decisões que também não podem e não devem ser totalmente conscientes, pelo menos no plano estético (Duchamp in Battcok, 1986, p. 71).

Corroborando com a análise de Duchamp, Rancière afirma que "a arte faz política antes que os artistas o façam" (2010, p. 51) e a estética é o que está em jogo nessa política como forma sensível na experimentação de um espaço e um tempo singulares. Posta essa relação, o que há de comum entre a arte e a política é a produção de ficções: uma reorganização sensível entre o dito e o não dito, entre o visível e o não visível, entre o que se mostra e os regimes de significação alavancados nesse jogo.

Produzir ficções não significa criar representações, teatralizar um acontecimento. O princípio da ficção é justamente produzir um recorte inédito da realidade, a partir de um agenciamento de regimes heterogêneos. Ela propõe uma configuração 
inédita dos espaços, dos tempos e dos lugares e quem possui determinada parcela dessa nova configuração. Assim, Gordura Trans \#3/Gordura Localizada \#1 consegue deslocar estes atributos do real e produzir uma nova partilha do sensível (Rancière, 2009), na qual o corpo do performer ocupa lugar privilegiado, onde em outra situação ele estaria sujeitado à normas de apresentação baseadas em uma moral recalcitrante. A ficção produzida no contexto de Gordura Saturadas reconfigura as formas sensíveis da experiência vivida, cria condições de possibilidades para um recorte espaço-temporal sobre o qual se torna possível um novo modo de subjetivação, o qual Jacques Rancière chama de "subjetivação política", suscitando novos dissensos, ou seja, conflitos sobre a própria configuração do sensível.

Uma subjetivação política é uma capacidade de produzir essas cenas polêmicas, essas cenas paradoxais que revelam a contradição de duas lógicas, ao colocar existências que são ao mesmo tempo inexistências ou inexistências que são ao mesmo tempo existências (Rancière, 1996, p. 52).

Há subjetivação política quando o acontecimento-limite engendra processos de desidentificação, quando os sujeitos em questão se descolam de uma experiência de si anterior. Acontecimentos-limite ou experiências-limite são decisivos, problematizam um "antes" e agenciam novos possíveis para um "depois". Neste sentido, a subjetivação política é um processo que produz sentidos e significados inéditos para a experiência vivida e possibilita o devir ativo de novas formas de vida. A desidentificação pressupõe uma série de fraturas na ortodoxia: são os rasgos que a performance tornou possíveis na experiência com o outro. Os modos de subjetivação política agenciam movimentos capazes de "arrancar a naturalidade de um lugar" (Rancière, 1996, p. 48), mudando os pontos de vista e reorganizando os sentidos compartilhados em comunidade, produzindo, assim, uma nova ficção.

A produção de cenas polêmicas em Gordura Trans \#3 / Gordura Localizada \#1 reorganiza os sentidos sobre o corpo, sobre os tempos e os espaços partilhados, sobre os direitos de fala e pertencimento. Estas cenas polêmicas são nada menos que ficções, que tensionam os dados da experiência sensível e desorganizam a funcionalidade dos tempos, dos lugares, das ocupações e dos sujeitos que ali são recriados. Dito de outro modo, o que está em jogo é uma relação de forças ativas (performance) e reativas (senso comum) produzida no contexto da performance, elementos heterogêneos que entram em agenciamento para constituir um novo corpo a partir do encontro. Desta heterogênese, espera-se toda sorte de possibilidades de graus de composição e graus de decomposição. Podemos afirmar que os processos de composição produzem movimentos que afirmam um devir ativo do corpo, possibilitando que o sujeito ultrapasse a si próprio a partir da experiência e efetue sua potência na reinvenção de si. Do contrário, entendemos que os processos de decomposição produzem a negação desse devir ativo do corpo a partir de forças reativas e, mais que isso, é seu perpétuo combate em nome da norma e de um modelo moral das formas de vida. 


\section{Saturações}

Certamente é impossível antecipar uma experiência, pois ela é sempre singular e única em cada termo do acontecimento para cada corpo relacionado. Procuramos, neste artigo, criar aproximações com os rastros sensíveis da performance e analisar os possíveis graus de composição e decomposição agenciados no encontro dos corpos no contexto da performance.

Muito embora possamos acessar rastros sensíveis da performance que, ao exprimir as passagens e permanências da experiência, indicam as reverberações alavancadas no acontecimento, não há como precisar os fluxos ativos ou reativos. A produção de subjetividade política implica movimento, necessita que forças ativas sejam produzidas em um circulo virtuoso da potência. Entretanto, a produção de forças reativas, de subjetividades assujeitadas, que é operada simultaneamente em diferentes corpos, mostra que nem sempre a performance, apesar de apresentar-se politizada ou engajada, conforme analisado anteriormente, produz política, pois a política em si é indiferente $a$ isso. De acordo com Jacques Rancière, "não existe sempre política. Ela acontece, aliás, muito pouco e raramente" (Rancière, 1996, p. 31), pois depende sempre da heterogênese de cada encontro. A política é casuística.

Os modos de subjetivação política são rarefeitos e implicam atividade, no sentido de que só podemos ser ativos na medida em que efetuamos algum tipo de realidade descolada do consenso, a partir das forças contrárias que nos constituem. Ser ativo é raro, pois implica um retorno da força sobre si mesma; é um círculo virtuoso da potência, a afirmação da diferença que nos constitui e que exprime as singularidades de cada forma de vida, afirmação que também é resistência, um dizer-sim criador.

Cada processo de subjetivação engendrado no encontro com a performance de Miro Spinelli, segue fluxos próprios, únicos em sua radical singularidade, porém, podendo escoar por duas vias distintas, ativas ou reativas. Significa dizer que nem toda performance age de modo a produzir forças ativas, pois nem sempre consegue- se mudar os pontos de vista, produzir sentidos novos ou formas que possibilitam os corpos envolvidos experimentarem graus de liberdade e reorganizarem suas noções de pertencimento, suas distribuições de tempos e espaços em um recorte comum partilhado.

Quando a performance perturba essa distribuição da comunidade, através da produção de cenas polêmicas, ela agencia movimentos que desorganizam a funcionalidade da partilha (Rancière, 2009), instaurando desse modo uma comunidade litigiosa, uma comunidade política que produz potência sobre si mesma e faz variar suas experiências comuns sobre o real.

O corpo é um complexo território, povoado por afetos contrários, distribuindo as intensidades que recebe nos tempos e espaços em sua extensão e pensamento. Os acontecimentos estéticos engendrados pela performance - e não somente por ela, mas também através de outras modalidades de objetivação estética - são entendidos nesse contexto como discursos provisórios sobre as conversações à respeito do que pode o corpo, tal como analisado por Spinoza e seus interlocutores.

A questão levantada buscou refletir sobre o que está no centro das práticas es- 
téticas que trazem o corpo como plataforma operativa e pautam seu discurso sobre ele, desorganizando e possibilitando a constituição de novos planos de composição, fazendo emergir na realidade, objetos inéditos que se dão a ver e a sentir. Os modos de fazer e os modos de visibilidade operam em Gordura Trans uma aesthesis ${ }^{10} \mathrm{com}$ partilhada em comunidade, arrancando a naturalidade do hábito assentado sobre os tempos e os espaços vividos e configurados pela doxa.

Entendemos que neste tipo de prática artística habita uma força singular de produção heterogenética na constituição de novas formas de vida ou novos modos de pensabilidade sobre a experiência do real, ou seja, a produção de sentidos e significados inéditos, possíveis a partir de uma variação dos dados da experiência sensível proporcionados pelo encontro com a performance.

A heterogênese é um movimento de composição que se dá do encontro de elementos singulares, quase sempre contrários, que se constituem a partir dos corpos do artista, do público e de um terceiro corpo, que é o próprio campo estético produzido por este encontro. Esse agenciamento de forças contrárias possibilita a emergência de fluxos que fogem da lógica hegemônica e das dinâmicas que configuram uma ficção consensual, desfazendo hierarquias e rompendo qualquer acordo entre o dito, o mostrado, o aceitável, o possível e o real.

Neste sentido, a performance movimenta forças de resistência, ao produzir fluxos ativos para o engendramento de subjetivação política que se lançam sobre as forças reativas do hábito e do senso comum - ou da doxa. Enfim, mesmo que a política esteja desobrigada da performance, mesmo que ela ocorra muito pouco e por pouco tempo, independente da vontade do artista, os vetores da apresentação agem sempre em prol de uma experiência estética capaz de produzir uma ficção que suspenda as lógicas de apresentação sensível de tempo-espaço partilhado, promovendo processos de subjetivação inéditos ao desconectar e operar deslocamentos do sensível, arrancando-o do ordinário e do comum.

A política da arte é essa tensão, mantida de forma necessariamente inadvertida pela apresentação de um acontecimento estético que agencia corpos em experiências inéditas, que deslocam as lógicas consensuais a partir da constituição de cenas polêmicas sobre o real, ao mesmo tempo em que podem reiterar forças reativas, o que faz com que a política dependa do encontro, caso a caso, para se efetuar em um tempo-espaço partilhado. As lógicas e dinâmicas sensíveis que se operam sobre o real são uma questão de composição ou decomposição e estas, por sua vez, são uma questão de encontro.

\section{Referências}

DELEUZE, Gilles; GUATTARI, Félix. 28 de novembro de 1947 - Como criar para si um Corpo Sem Órgãos?. In: Mil platôs: Capitalismo e Esquizo-

\footnotetext{
${ }^{10}$ Aisthesis é o termo grego que designa as capacidades de perceber e sentir do corpo. A filosofia tomou esta relação da percepção do corpo com o mundo para fundar a Estética, ramo que se dedica a estudar a relação da percepção do corpo com a arte e como as formas sensíveis são capazes de produzir determinados arranjos na produção de sentidos do sujeito. Vem se desenvolvendo e mudando desde Baumgarten, passando por Sanchez Vázquez até os mais contemporâneos como Jacques Rancière. Uma aisthesis compartilhada em comunidade, portanto, diz dos modos de relação e produção de sentidos de um determinado grupo a partir de um acontecimento experienciado num contexto comum.
} 
frenia 2, vol. 03; trad. Aurélio Guerra Neto, Ana Lúcia de Oliveira, Lúcia Cláudia Leão e Suely Rolnik. São Paulo: Editora 34, 2012, p. 11 - 34;

DUCHAMP, Marcel. O ato criador. In: BATTCOCK, Gregory. (Org.). A nova arte. São Paulo: Perspectiva, 1986, p. 71 - 74;

FABIÃO, Eleonora. Teatro e Performance: poéticas e políticas da cena contemporânea. Rev. Sala Preta, № 08. São Paulo: Ed. USP, 2008, p. 235 - 246;

FOUCAULT, Michel. Nascimento da biopolítica. In: Resumo dos Cursos do College de France (1970-1982). Rio de Janeiro: Jorge Zahar, 1997, p. 911;

RANCIÈRE, Jacques. O desentendimento: filosofia e política; Trad. Angela Leite Lopes. São Paulo: Ed. 34, 1996;

A partilha do sensível: Estética e política. Trad. Monica Costa Netto.

São Paulo: Ed. 34. 2ª Edição, 2009.

Política da arte; trad. Mônica Costa Netto. In: Urdimento - Revista de Estudos em Artes Cênicas / Universidade do Estado de Santa Catarina. Programa de Pós-Graduação em Teatro. - Vol. 1, n. 15 (Out. 2010) - Florianópolis: UDESC/CEART, p. $45-60$.

ROLNIK, Suely. O retorno do Corpo-que-Sabe. In: Hemispheric Institute of Performance and Politic, 88 min, 2013. Disponível em: http://hemisphericinstitute.org/ hemi/pt/enc13-keynote-lectures/item/2085-enc13-keynote-rolnik. Acessado em março de 2017.

SPINELLI, Miro. Gordura Trans, 2015. Disponível em: http://gordura-trans.tumblr. com/. Acessado em março de 2017.

SPINOZA, Baruch de. Ética; trad. Tomaz Tadeu. $2^{\underline{a}}$ ed. Belo Horizonte: Autêntica Editora, 2014a.

Breve tratado de Deus, do homem e do seu bem-estar; trad. Emanuel Angelo da Rocha Fragoso e Luís César Guimarães Oliveira. Belo Horizonte: Autêntica Editora, 2014b.

Recebido em: 29/03/2017

Aprovado em: 24/08/2017 